\title{
ESTUDOS SOBRE EGRESSOS EM BIBLIOTECONOMIA A PARTIR DA BASE DE DADOS EM CIÊNCIA DA INFORMAÇÃO - BRAPCI
}

\author{
VAGNER IVAN DE ALENCAR GOMES \\ LUCIANA DE ALBUQUERQUE MOREIRA**
}

\begin{abstract}
RESUMO
O olhar para o egresso em Biblioteconomia é também uma forma de enxergar o mercado de trabalho que ele ocupa atualmente. Nesse sentido, este artigo apresenta os resultados de uma pesquisa cujo objetivo geral foi de fazer um levantamento das pesquisas divulgadas que tratam do tema 'egresso em Biblioteconomia', indexadas pela Base de Dados Referenciais de Artigos de Periódicos em Ciência da Informação - BRAPCl. Para isso, buscou-se identificar a quantidade de estudos recuperados e apontar as metodologias usadas nessas pesquisas. Como procedimento metodológico, foi empregada a pesquisa bibliográfica, quali-quanti, e como fonte de pesquisa, a BRAPCI. A análise procedeu a partir da recuperação dos artigos cujas palavras-chave traziam os termos 'egresso', 'mercado de trabalho' e 'ex-aluno'. O levantamento resultou em 14 estudos recuperados de acordo com a palavra-chave 'egresso', 100 produções com o termo 'mercado de trabalho' - 13 dos quais abordam o tema 'egresso de Biblioteconomia' - e um artigo relativo ao termo 'ex-aluno'. O recorte temporal abrangeu o período de 1972 a 2017, totalizando 45 anos de estudos, exibe os objetivos das pesquisas apontados pelos autores e mostra que as metodologias utilizadas nos artigos foram a pesquisa descritiva, a exploratória, a quantitativa, a qualitativa e o levantamento bibliográfico, e como principal instrumento de coleta de dados, o questionário. A pesquisa mostrou que existem poucos estudos que foram recuperados pela Base de dados BRAPCl, razão por que é necessário realizar pesquisas relacionadas aos 'egressos', devido à sua importância para o planejamento de ações contínuas e voltadas para eles na própria universidade formadora.
\end{abstract}

PALAVRAS-CHAVE: Egresso; bibliotecário; BRAPCI; Produção científica; Ciência da Informação.

\footnotetext{
*Bacharel em Turismo (UFRN), graduando em Biblioteconomia (UFRN). Bolsista de Iniciação Científica-PIBIC-UFRN.

* Professora Associada do Departamento de Ciência da Informação, atuando no curso de graduação em Biblioteconomia e no Mestrado Profissional em Gestão da Informação e do Conhecimento.
} 


\begin{abstract}
Analyzing library science graduates' perception is a form of perceiving the current job market. In this sense, this article presents the results of a research whose general objective was to analyze published research that deal with the subject "library science graduates" indexed by the Base de Dados Referenciais de Artigos de Periódicos em Ciência da Informação - BRAPCI. Thus, the research aimed to identify the number of studies and point out the methodologies used in these results. The methodological procedure used were bibliographical research, a qualitative and quantitative approach as well as research performed in the database. Results included the presence of key-words such as "graduates", "labor market", "ex-student". In total there were 14 articles that included the term "alumni", 100 with "labor market", of these 13 studies that deal and 1 article with "ex- student". The study covered the period from 1972 to 2017, totaling 45 years of studies. It was seen that the methodologies used in the articles are of descriptive, exploratory, bibliographical, quantitative and qualitative survey, using questionnaires for data collection purposes. It is possible to conclude that there are still few studies that deal with the aforementioned subject the BRAPCI Database making it necessary to produce further research in this field considering its importance for the planning of continuous and important academic actions.
\end{abstract}

KEYWORDS: Library Science graduates. BRAPCI. Scholarly Production. Information Science.

\title{
1. INTRODUÇÃO
}

As transformações ocorridas na sociedade, tanto no contexto social quanto no econômico e no político, evidenciam um "crescimento exponencial e uma valorização proporcional atribuída à informação". (MOREIRA, 2018, p. 17). Por essa razão, são essenciais as categorias de profissionais da informação para lidarem com a grande quantidade de informações presentes na sociedade, entre eles, o bibliotecário.

Devido às tantas mudanças em relação à principal "ferramenta" de trabalho do bibliotecário - a informação - e sua inserção em todos os âmbitos, é natural que o bibliotecário, acompanhando a própria transformação da sociedade, também encontre novos espaços de atuação, novas metodologias de trabalho e, finalmente, seja reconhecido na "sociedade da informação" como um importante agente de transformação social. Por isso é importante realizar pesquisas voltadas para o bibliotecário e para o mercado de trabalho, a partir dos egressos já formados pelas universidades. 
Carvalho e Barbosa Neto (2016, p. 3) asseveram que, "para analisar o mercado de trabalho do bibliotecário, é preciso levar em consideração o contexto de formação desse profissional, as mudanças paradigmáticas ocorridas na área e, de forma geral, a percepção da importância atribuída à informação". Nesse sentido, é necessário direcionar o olhar para a formação dos futuros bibliotecários e para os egressos, como forma de acompanhar 0 desenvolvimento profissional e proporcionar, por parte dos cursos, uma educação continuada para esse público.

Nessa perspectiva, surgiu a curiosidade acadêmica em relação ao tema 'egresso'. Será que esse tema está sendo abordado e discutido nas pesquisas feitas na área de Ciência da Informação? Nesta pesquisa, o intuito é de saber qual a quantidade de estudos/pesquisas voltados para o tema 'egressos em Biblioteconomia' que estão sendo produzidos e divulgados em periódicos da área por meio da Base de Dados Referenciais de Artigos de Periódicos em Ciência da Informação - BRAPCI?

Este artigo apresenta os resultados de uma pesquisa, cujo objetivo principal foi o de relacionar os estudos sobre o tema 'egresso em Biblioteconomia', indexados pela Base de Dados Referenciais de Artigos de Periódicos em Ciência da Informação (BRAPCI) a partir das palavras-chave 'egresso', 'mercado de trabalho' e 'ex-aluno'. Para isso, buscou-se identificar a quantidade de estudos recuperados e apresentar seus objetivos e as metodologias empregadas nas pesquisas publicadas.

Esse relato visa incitar uma reflexão sobre o mercado em que o bibliotecário atua, sob o ponto de vista dos egressos, como fonte de informação. A reflexão sobre as ações se estende à própria formação desse profissional, portanto, é sobremaneira importante olhar não apenas para o aluno em formação, mas também para além dos muros das universidades. Neste artigo, a abordagem partiu de uma importante base de dados, a BRAPCl, porque se acredita que a divulgação científica é a base para formar um corpus necessário para conscientizar e fortalecer uma temática específica.

\section{PRODUÇÃO CIENTÍFICA: BREVE CONTEXTO}

Antes de abordar o tema produção científica, é necessário fazer uma breve exposição sobre um tema diretamente relacionado à produção - a comunicação científica - que é "um elemento responsável por novos achados, advindos de trabalhos exaustivos de cientistas e pesquisadores, a quem compete não apenas 
a produção de novos conhecimentos, mas, também, a avaliação dos resultados advindos dos pares". (TARGINO; TORRES, 2014, p. 4).

Para Caribé (2015), a comunicação científica

engloba todas as demais formas de comunicação que variam de acordo com o tipo de linguagem utilizada ou com o tipo de entidade do processo de comunicação ao qual encontra-se relacionado. Incorpora tanto a comunicação interna dirigida à comunidade científica quanto à externa, destinada ao público leigo. (CARIBÉ, 2015, p. 101).

Em relação a produção científica, o estudo baseou-se em Oliveira e Grácio (2009, p. 4), em que é conceituada como "o conjunto de publicações geradas durante a realização e após o término de pesquisas". Nota-se que pesquisa está totalmente associada tanto à comunicação científica quanto à produção científica. Nesse sentido, Caribé (2015) apresenta os processos da comunicação científica com base em um modelo.

Figura 1 - Modelo de comunicação científica - processos

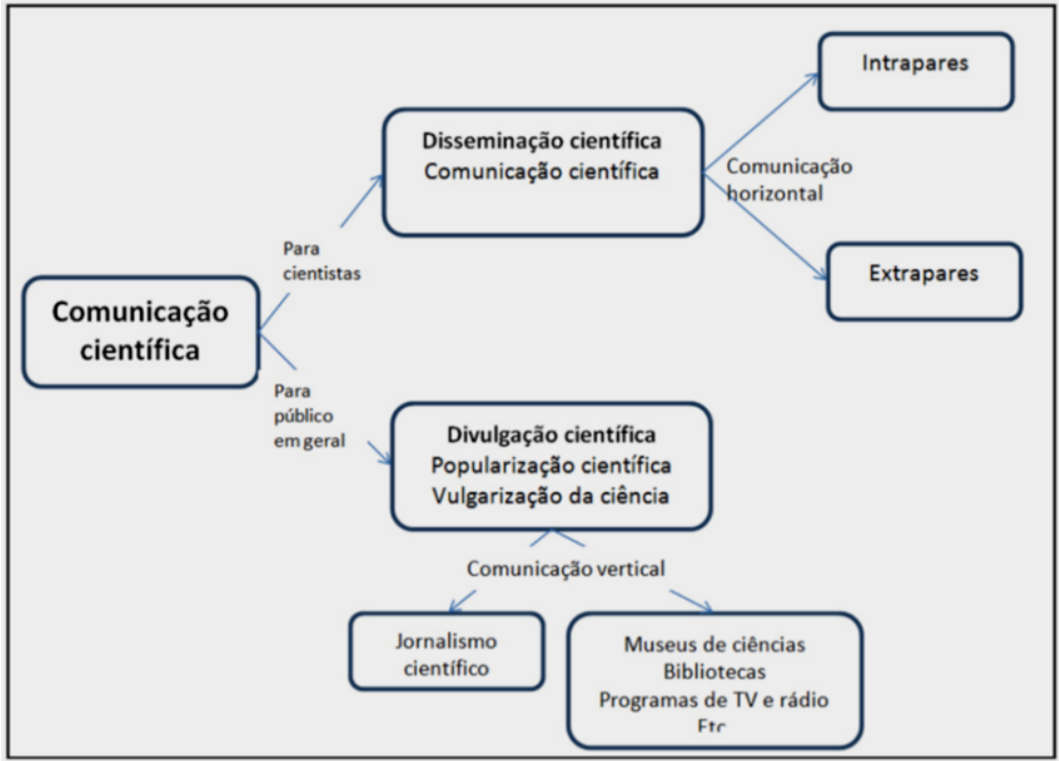

Fonte: Caribé (2015, p. 101)

No modelo apresentado, a comunicação científica é disseminada para cientistas por meio de canais horizontais 
(intra e extrapares), e para o público em geral, utiliza-se de um movimento vertical de divulgação, que tem como sinônimo a popularização ou vulgarização da ciência. Nele, são representantes, de um lado, o jornalismo científico, e, de outro, os museus de ciências e as bibliotecas, como exemplos da verticalização da comunicação científica.

Percebe-se que a produção científica tem sua importância no contexto acadêmico. A esse respeito, Bernardino e Alentejo (2014, p. 5) referem que "estudos sobre a produção científica de determinada área da ciência se justificam pela importância acadêmica, pois ela avalia o crescimento científico do pesquisador ou da instituição que o abriga". Isso mostra o quanto é importante a produção científica, tanto para as instituições e para os pesquisadores quanto para determinada área do conhecimento. Vale lembrar que "uma das formas de transmitir os resultados de pesquisas é a publicação de artigos em periódicos científicos, de livros e capítulos de livros". (MEDEIROS; VILAN FILHO, 2016, p. 35).

Assim, devido à relevância da produção científica, percebeu-se que "analisar a produção do conhecimento científico se tornou uma tarefa muito utilizada nas últimas décadas, pois, através dela, é possível entender, mesmo em meio a tanta informação, como determinado campo de saber vem se desenvolvendo" (MARCELO; HAYASHI, 2013, p. 139).

Esse olhar para o campo da Biblioteconomia foi dirigido a partir das pesquisas divulgadas na Base de Dados Referenciais de Artigos de Periódicos em Ciência da Informação - BRAPCl.

\section{BREVES RELATOS SOBRE A FORMAÇÃO E A ATUAÇÃO DO BIBLIOTECÁRIO}

A formação do bibliotecário deve refletir o contexto social ao qual pertence e, a partir de então, fortalecer e praticar essa formação nas ações empreendidas no mercado de trabalho. A título de exemplo, aponta-se a perspectiva adotada no Projeto Pedagógico do Curso de Biblioteconomia da Universidade Federal do Rio Grande do Norte, do qual se destaca a seguinte passagem:

A Biblioteconomia e a sua formação não estão deslocadas do contexto maior, das transformações da sociedade que ocorrem em uma velocidade cada vez mais acelerada, sobretudo devido às tecnologias de informação e comunicação. Essas mudanças influenciam as organizações, as relações humanas e principalmente o mercado de trabalho. Dessa forma, são necessárias propostas 
educacionais diferenciadas rumo a um 'saber ser, saber fazer e saber agir', bem como a existência de novas formas de comunicação através de informações veiculadas em diferentes suportes e formatos informacionais. (PROJETO..., 2017, p. 4).

Complementar a essa visão holística da formação, destaca-se a grande valorização dada à informação nas últimas décadas. Valentim (2000) aponta que, "atualmente, as estruturas dos cursos estão, na sua maioria, direcionadas para o paradigma da informação, buscando um profissional dinâmico e competitivo que de fato atenda aos anseios da sociedade brasileira". (VALENTIM, 2000, p. 8).

As Diretrizes Curriculares para os Cursos de Biblioteconomia trazem, no Parecer CNE/CES 492/2001 (2001, p. 32-33), e as competências e as habilidades dos graduados em Biblioteconomia, categorizadas em gerais e específicas. São elas:

A) Gerais

- Gerar produtos a partir dos conhecimentos adquiridos e divulgá-los;

- Formular e executar políticas institucionais;

- Elaborar, coordenar, executar e avaliar planos, programas e projetos;

- Utilizar racionalmente os recursos disponíveis;

- Desenvolver e utilizar novas tecnologias;

- Traduzir as necessidades de indivíduos, grupos e comunidades nas respectivas áreas de atuação;

- Desenvolver atividades profissionais autônomas, de modo a orientar, dirigir, assessorar, prestar consultoria, realizar perícias e emitir laudos técnicos e pareceres;

- Responder a demandas sociais de informação produzidas pelas transformações tecnológicas que caracterizam o mundo contemporâneo.

B) Específicas

- Interagir e agregar valor nos processos de geração, transferência e uso da informação, em todo e qualquer ambiente;

- Criticar, investigar, propor, planejar, executar e avaliar recursos e produtos de informação;

- Trabalhar com fontes de informação de qualquer natureza;

- Processar a informação registrada em diferentes tipos de suporte, mediante a aplicação de conhecimentos teóricos 
e práticos de coleta, processamento, armazenamento e difusão da informação;

- Realizar pesquisas relativas a produtos, processamento, transferência e uso da informação.

Além dessas, Valentim (2002) aponta quatro categorias de competências associadas aos profissionais da informação: 1. Competências de comunicação e expressão; 2. Competências técnico-científicas; 3 . Competências gerenciais e 4. Competências sociais e políticas. (VALENTIM, 2002, p. 123-125).

O acesso, o uso e a disseminação da informação têm se popularizado com a tríade basilar de competências e habilidades do bibliotecário. No entanto, Paletta e Silva (2017) alertam:

É preciso atentar para o fato de que não é possível mais se limitar à tarefa de localizar fontes de informação. É necessário levar em consideração tarefas de interpretação, formulação e aprendizagem envolvidas no processo de busca dessa informação. O aumento no acesso à vasta quantidade de informação requer, entretanto, serviços que se centrem no significado da busca mais do que meramente na localização da fonte. Nessa perspectiva, os usuários da informação não podem ser vistos apenas como integrantes do sistema, mas como a "razão de ser" do serviço de informação. (PALETTA; SILVA, 2017, p. 168).

Portanto, o mercado digital se integra às competências já conhecidas dos bibliotecários, expandindo ainda mais as possibilidades de atuar e inovar no mercado da informação.

Convém ressaltar, ainda, que a profissão do bibliotecário é regulamentada pela Lei $n^{\circ} 4.084$, de 30 de junho de 1962, que dispõe sobre a profissão de bibliotecário e regula seu exercício. Essa regulamentação foi estabelecida há cinquenta e sete anos. Porém, apesar de ser uma profissão sólida, os profissionais e os órgãos de formação devem estar sempre atentos às transformações existentes na sociedade contemporânea, com toda a dinamicidade das ações relacionadas à informação.

\section{PERCURSO METODOLÓGICO}

Toda pesquisa, para ser desenvolvida, percorre um caminho até chegar aos resultados. Assim, para alcançar os objetivos propostos nesta pesquisa, foi feita uma análise na Base de Dados Referenciais de Artigos de Periódicos em Ciência da Informação (BRAPCl). A BRAPCl é uma importante fonte de informação 
em se tratando de publicações periódicas. Nesse sentido, é relevante observar o crescimento exponencial no número de publicações periódicas na área de Ciência da Informação no Brasil. Diversos fatores colaboraram para isso, dentre eles, a facilidade de utilizar plataformas digitais para abrigar o periódico, que barateiam e facilitam a divulgação por meio de acesso livre aos seus conteúdos.

A BRAPCl nasceu de um projeto intitulado 'Metodologia para criação de uma base de dados online de acesso público: modelizando práticas para a socialização de saberes', de autoria de Leilah Santiago Bufrem e aprovado pelo Conselho Nacional de Pesquisa (CNPq). Atualmente é intitulado de Conselho Nacional de Desenvolvimento Científico e Tecnológico e resultou na consolidação como também na disponibilização da BRAPCl ao público. (GABRIEL JUNIOR, 2014).

De acordo com Bufrem (2013, p. 75), a BRAPCl tem o "intuito de facilitar a pesquisa de documentos e artigos da área". Quanto aos tipos de publicação contidos nessa base, tem-se: 57 revistas científicas, 2.592 trabalhos em eventos, 19.179 trabalhos em revistas científicas, uma tese e dois livros, com representação de 16.601 autores, tendo como responsável a Universidade Federal do Paraná - UFPR. (BRAPCIP, 2018). A escolha dessa base de dados como objeto de análise desta pesquisa se justifica por causa de sua importância. Na Figura 2, a seguir, tem-se uma imagem da BRAPCI.

Figura 2 - Site da Base de Dados - BRAPCI

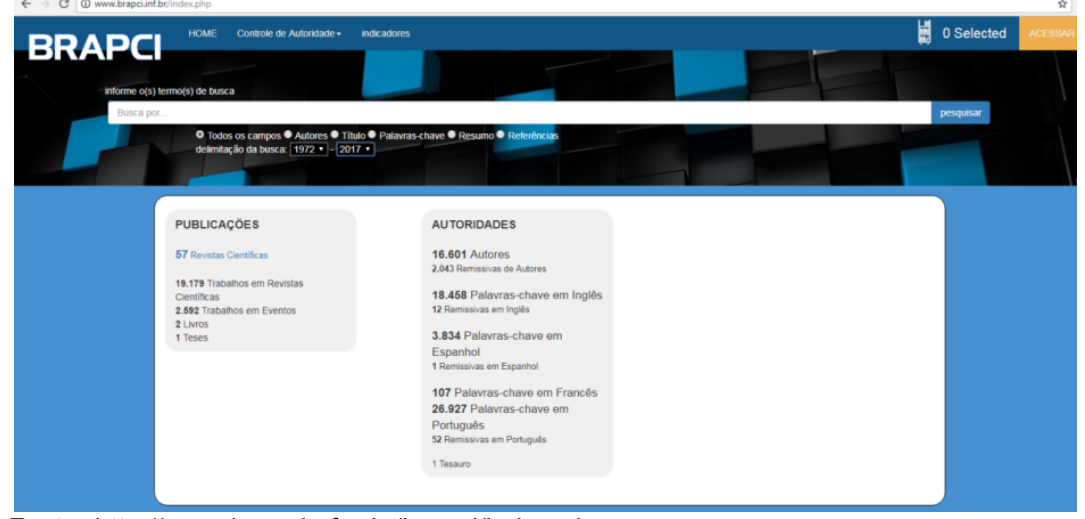

Fonte: http://www.brapci.ufpr.br/brapci/index.php

A Figura 2 indica que a BRAPCI tem representatividade na área de Ciência da Informação, portanto, é um relevante ambiente para se investigar sobre produção científica a partir de pesquisas 
sobre egressos. Nesse sentido, apresenta-se o percurso utilizado para alcançar os objetivos propostos.

Para a realização deste estudo, foram seguidos estes procedimentos metodológicos: pesquisa bibliográfica, pesquisa qualiquanti, tendo em vista que a seleção foi realizada quantificando as publicações em que aparecem os termos 'egresso', 'mercado de trabalho' e 'ex-aluno', e qualitativa, porquanto se procedeu à leitura dos resumos para identificar o tema e das produções por completo, buscando-se, mais precisamente, duas categorias de análise: os objetivos e a metodologia empregados nas pesquisas.

Os dados foram coletados inteiramente na BRAPCI. Foi realizado o levantamento bibliográfico dos estudos produzidos sobre o tema 'bibliotecário egresso'. Assim, acessou-se a BRAPCl e, no campo de busca, foi inserido o termo 'egresso', selecionada a opção de busca 'palavras-chave', e a pesquisa foi delimitada para os anos de 1972 a 2017. A extensão desse período foi proposital e visou analisar todas as produções indexadas na BRAPCl. Assim, nosso recorte foi finalizado para o ano de 2017.

O levantamento foi feito no dia 12 de setembro de 2017 e foram recuperadas 12 produções. Depois da etapa de seleção, realizou-se a leitura dos resumos para identificar/analisar os estudos que realmente eram fiéis ao tema 'egressos de Biblioteconomia'. Dos 12 estudos recuperados por meio da palavra-chave 'egresso', houve duplicidade de formatos de um mesmo estudo, que foi recuperado tanto em formato de resumo quanto de artigo completo em diferentes revistas. Dentre as produções recuperadas na $\mathrm{BRAPCl}$, por meio da análise realizada, só foram obtidos três estudos relacionados especificamente ao tema 'bibliotecário egresso'.

No decorrer do estudo, notou-se a necessidade de realizar uma nova pesquisa, com o intuito de recuperar os trabalhos relacionados ao tema mercado de trabalho - egresso. Assim realizou-se uma nova busca no dia 10 de março de 2018, com o objetivo de ampliar o corpo do trabalho e atualizar os dados referentes a eles. Para isso, foram inseridos os termos 'egresso', 'mercado de trabalho' e 'ex-aluno' e selecionada a opção de busca 'palavras-chave', delimitando no menu a pesquisa de 1972 a 2017.

A estratégia de realizar a pesquisa a partir das palavras-chave registradas pelos autores deveu-se, principalmente, à sua representatividade nas pesquisas e para valorizar o uso correto do termo escolhido pelos autores para facilitar a busca e a recuperação dos artigos inseridos na BRAPCl. Compartilha-se com o pensamento de Miguéis et al (2013, p. 115), quando afirmam que 
o uso das palavras-chave potencia o acesso ao conteúdo dos documentos, para além da informação que é representada pelo título e resumo; traduz o pensamento dos autores, e mantém o contacto com a realidade da prática quotidiana, acompanhando a evolução científica e tecnológica, que é refletida pelos documentos.

Ao realizar a pesquisa utilizando a palavra-chave 'mercado de trabalho', foram recuperadas 100 produções. Assim, realizou-se a leitura dos resumos dos artigos, com o objetivo de identificar estudos voltados para o mercado de trabalho do bibliotecário egresso. Só foram encontrados oito artigos.

Depois da etapa de seleção, os resumos desses artigos foram lidos para identificar/analisar os estudos que realmente eram fiéis ao tema pesquisado. $\mathrm{Na}$ análise dos artigos, percebeu-se que, dos 14 estudos recuperados por meio da palavra-chave 'egresso', houve duplicidade de formatos de um mesmo estudo, que foi recuperado tanto em formato de resumo quanto de artigo completo, em diferentes revistas, e um estudo foi recuperado ainda que não contivesse a palavra-chave 'egresso'. Depois de analisar as produções recuperadas na $\mathrm{BRAPCl}$, o número de artigos foi reduzido para quatro estudos sobre o tema 'bibliotecário egresso'.

$\mathrm{Na}$ expectativa de ampliar o número de estudos realizados, adotou-se mais uma palavra-chave: 'ex-aluno', por meio da qual só foi recuperada uma produção.

Apesar de ser um termo comum e utilizado com frequência no cotidiano, não é o correto a ser adotado. Para ratificar essa observação, recorreu-se a Coelho (2008, p. 110), que define o egresso como

aquele que saiu de determinada instituição de ensino após a conclusão dos estudos amparado pela certificação ou diploma legal. Egresso não é, portanto, aquele que abandonou a instituição ou dela foi expulso. O egresso é aquele que saiu da referida instituição, após a aprovação em exames e conclusão de uma carga horária curricular específica.

A partir dessa concepção, pode-se afirmar que o termo mais adequado para ser usado nas pesquisas, de fato, é egresso, porque todo egresso é um ex-aluno, mas nem todo ex-aluno é um egresso. $O$ baixo índice de documentos recuperados com esse descritor indica o pouco uso do termo. Isso significa que é preciso usar o descritor correto, que é 'egresso'. 


\section{APRESENTAÇÃO E DISCUSSÃO DOS RESULTADOS}

Depois de fazer o levantamento bibliográfico na BRAPCI, a partir dos termos de busca 'egresso', 'mercado de trabalho' e 'ex-aluno', pôde-se visualizar o número de produções relacionadas aos termos, num espaço temporal de 45 anos. A seguir, serão expostos os resultados, inicialmente, dos artigos recuperados pelo termo 'egresso', depois, pelo termo 'mercado de trabalho' e, por fim, 'ex-aluno'.

\subsection{Produção científica dos trabalhos recuperados a partir da palavra-chave 'egresso'}

Como já foi comentado, o levantamento bibliográfico na base $\mathrm{BRAPCl}$, a partir do termo de busca 'egresso', restringiu o número de 14 trabalhos publicados para quatro. O Quadro 1 aponta mais detalhes sobre os artigos publicados.

Quadro 1 - Levantamento dos artigos recuperados pela palavrachave 'egresso'

\begin{tabular}{|c|c|c|c|c|}
\hline Atores & Título & Palavras-chave & Periódico & Ano \\
\hline \begin{tabular}{|c|} 
MÜLLER, \\
Mary Stela; \\
FERNANDES, \\
Rogério Paulo \\
Müeller; \\
SANCHES, \\
Mônica \\
Sambudio.
\end{tabular} & $\begin{array}{l}\text { Com a palavra, } \\
\text { os egressos...: } \\
\text { avaliação do } \\
\text { curso de } \\
\text { Biblioteconomia } \\
\text { da UEL }\end{array}$ & \begin{tabular}{|c|} 
Biblioteconomia; \\
Formação \\
bibliotecária; \\
Curso de \\
Biblioteconomia \\
da UEL - \\
Avaliação; \\
Egressos.
\end{tabular} & $\begin{array}{c}\text { Informação \& } \\
\text { Informação, } \\
\text { v. } 3, \text { n. } 2 \\
\text { p. } 43-64,1998 .\end{array}$ & 1998 \\
\hline MACHADO, G. & \begin{tabular}{|c|} 
Um sistema de \\
acompanhamento \\
de egressos do \\
Curso de \\
Biblioteconomia \\
da Universidade \\
Federal do Rio \\
Grande do Sul \\
\end{tabular} & $\begin{array}{c}\text { Egresso; } \\
\text { Avaliação } \\
\text { institucional; } \\
\text { Ensino superior; } \\
\text { Mercado de } \\
\text { trabalho }\end{array}$ & $\begin{array}{c}\text { XII Encontro } \\
\text { Nacional de } \\
\text { Pesquisa em } \\
\text { Ciência da } \\
\text { Informação }\end{array}$ & $2011^{1}$ \\
\hline \begin{tabular}{|c|} 
SANTOS, \\
Charlene Maria \\
dos; \\
PINHO, \\
Fábio Assis.; \\
AZEVEDO, \\
Alexander \\
Wiliam.
\end{tabular} & \begin{tabular}{|c|} 
Perfil dos \\
egressos do \\
Curso de \\
Biblioteconomia \\
da Universidade \\
Federal de \\
Pernambuco \\
(2005 a 2010) \\
\end{tabular} & $\begin{array}{c}\text { Egressos; } \\
\text { Biblioteconomia; } \\
\text { Perfil } \\
\text { profissional; } \\
\text { UFPE }\end{array}$ & \begin{tabular}{|c|} 
Revista \\
Digital de \\
Biblioteconomia \\
\& Ciência da \\
Informação, \\
v. 11, n. 2, 2013
\end{tabular} & 2013 \\
\hline
\end{tabular}

${ }^{1}$ Esse documento não está exibido por completo na base de dados, apenas o resumo. 


\begin{tabular}{|c|c|c|c|c|}
\hline $\begin{array}{c}\text { FARIA, } \\
\text { Ana Carolina } \\
\text { Cintra; } \\
\text { CASTRO } \\
\text { FILHO, } \\
\text { Cláudio } \\
\text { Marcondes }\end{array}$ & $\begin{array}{l}\text { Profissional da } \\
\text { informação: } \\
\text { estudo dos } \\
\text { egressos no } \\
\text { estado de São } \\
\text { Paulo, mundo do } \\
\text { trabalho, } \\
\text { habilidades e } \\
\text { competências }\end{array}$ & $\begin{array}{l}\text { Profissional da } \\
\text { Informação; } \\
\text { Egressos; } \\
\text { Biblioteconomia; } \\
\text { Ciência da } \\
\text { Informação; } \\
\text { Competências; } \\
\text { Habilidades; } \\
\text { Perfil }\end{array}$ & $\begin{array}{c}\text { Ponto de } \\
\text { acesso, } \\
\text { v. 8, n. 3, } 2014 .\end{array}$ & 2014 \\
\hline
\end{tabular}

Fonte: Dados da pesquisa - 2018

Nota-se que os estudos são de anos e periódicos diferentes. O primeiro artigo é do ano de 1998 e foi publicado no volume 3 do número 2, pela Revista Informação \& Informação da Universidade Estadual de Londrina (UEL); o segundo foi publicado em 2011, no evento científico, XII Encontro Nacional de Pesquisa em Ciência da Informação (ENANCIB); o terceiro, de 2013, publicado no volume 11 do número 2 da Revista Digital de Biblioteconomia \& Ciência da Informação, da Universidade Estadual de Campinas (UNICAMP); e o último, publicado no ano de 2014, volume 8 , no número 3, do periódico Ponto de Acesso, da Universidade Federal da Bahia (UFBA). Percebe-se que os artigos publicados sobre o tema tiveram um longo período de silêncio, pois o primeiro estudo foi em 1998, e os demais, em 2011, 2013 e 2014.

Então, é preciso desenvolver mais pesquisas direcionadas ao tema 'egressos', como recomenda Carvalho e Barbosa Neto (2016, p. 16), quando afirmam que é necessário "investigar e analisar os egressos periodicamente, [...] em todo o Brasil, para ser construído de forma real e legítima um cenário sobre a situação dos egressos no mercado de trabalho e assim dialogar com as instâncias de formação acadêmica".

Em relação à categoria dos objetivos dos estudos publicados, o primeiro, de autoria de Müller; Fernandes e Sanches (1998, p. 44), teve os objetivos de

caracterizar o perfil acadêmico/profissional dos egressos; levantar aspectos positivos/negativos da formação recebida e seus reflexos na atuação profissional dos egressos; identificar necessidades de atividades de educação continuada dos egressos e obter sugestões para melhorar o curso.

No segundo artigo, foi exposto apenas o resumo na BRAPCI, mas foi possível visualizar o objetivo da produção de Machado $(2011)^{2}$, que foi de

${ }^{2}$ Documento não exibido por completo na base de dados, apenas o resumo. 
atribuir um significado à utilização de mecanismos de consulta aos egressos do Curso de Biblioteconomia da Universidade Federal do Rio Grande do Sul - UFRGS, ao avaliar a situação profissional dos egressos do Curso de Biblioteconomia em relação a aspectos de sua trajetória profissional, acadêmica e a expectativas de educação continuada e de participação de atividades na instituição.

O terceiro estudo, de autoria de Santos; Pinho e Azevedo (2013, p. 224), o objetivo geral foi o de

analisar o perfil dos egressos formados pelo Curso de Biblioteconomia da Universidade Federal de Pernambuco, no período de 2005 a 2010. Para isso, de forma mais específica, objetivou-se: (a) identificar as características pessoais dos egressos do curso no período de 2005 a 2010; (b) verificar a atividade profissional desses egressos; e, (c) identificar as relações desses egressos com a instituição que os formou.

No quarto e último estudo, Faria e Castro Filho (2014, p. 45) tiveram o objetivo de

apresentar o perfil dos egressos dos profissionais da informação do estado de São Paulo, que denominamos, nesta pesquisa, o profissional bibliotecário, como também, o seu mundo do trabalho e as suas competências e habilidades para a contribuição de um modelo de qualificação profissional condizente com o mundo contemporâneo.

Nota-se que três das pesquisas encontradas estão relacionadas à identificação do perfil dos egressos, seja na Universidade Estadual de Londrina (UEL), na Universidade Federal de Pernambuco e no Estado de São Paulo, nas três Universidades Públicas representadas pela Universidade Estadual Paulista (UNESP) de Marília, pela Universidade Federal de São Carlos (UFSCAR) e pela Universidade de São Paulo (USP), campus de Ribeirão Preto. Assim, esses estudos exibem o perfil dos egressos de diferentes regiões do Brasil, como a Região Sul, a Nordeste e a Sudeste. Já a produção de Machado (2011) aborda a trajetória profissional dos egressos ao realizar uma avalição desses profissionais.

Quanto ao número de palavras-chave registradas nos artigos, foram encontradas 19. As mais utilizadas pelos autores foram 'egressos, com quatro ocorrências, 'Biblioteconomia', com três, e as que surgiram apenas uma vez, sem que houvesse repetição, foram: Avaliação institucional, Ciência da Informação, Competências, 
Curso de Biblioteconomia da UEL - Avaliação, Ensino Superior, Formação bibliotecária, Habilidades, Mercado de trabalho, Perfil, Perfil profissional, Profissional da Informação e UFPE. No que diz respeito ao segundo ponto de análise dos artigos - as metodologias empregadas nesses estudos - todos adotaram como instrumentos de coleta de dados questionários com questões abertas e fechadas.

Quanto ao tipo de pesquisa utilizada nos estudos recuperados, na produção científica de Müller, Fernandes e Sanches (1998), foi empregada a descritiva, e como método, o levantamento bibliográfico. Na pesquisa de Machado (2011), não foram identificados o tipo de pesquisa, o método e o instrumento. Os autores Santos, Pinho e Azevedo (2013) optaram pela pesquisa exploratória, e os dados foram analisados de forma quali e quantitativa, tendo como método de pesquisa o levantamento bibliográfico. Não foi possível saber o tipo de pesquisa no artigo de Faria e Castro Filho (2014), que utilizaram como processo metodológico os estudos de Valentim (2000), que distribui o mercado de trabalho dos profissionais da informação nos grupos: "'mercado informacional tradicional', 'mercado informacional existente e pouco ocupado' e 'mercado informacional de tendências'”. (FARIA; CASTRO FILHO, 2014, p. 53).

Para facilitar a percepção, o Quadro 2 exibe o resumo das metodologias identificadas nos artigos.

Quadro 2 - Metodologias dos artigos recuperados pela palavra-chave 'egresso' relacionadas a bibliotecário egresso

\begin{tabular}{|c|c|c|c|c|c|}
\hline Atores & Título & $\begin{array}{l}\text { Tipo de } \\
\text { pesquisa }\end{array}$ & Método & Instrumento & Ano \\
\hline $\begin{array}{l}\text { MÜLLER, } \\
\text { Mary Stela; } \\
\text { FERNANDES, } \\
\text { Rogério Paulo } \\
\text { Müeller; } \\
\text { SANCHES, } \\
\text { Mônica } \\
\text { Sambudio }\end{array}$ & $\begin{array}{l}\text { Com a palavra os } \\
\text { egressos.: } \\
\text { avaliação do curso } \\
\text { de Biblioteconomia } \\
\text { da UEL }\end{array}$ & Descritiva & $\begin{array}{l}\text { Levantamento } \\
\text { bibliográfico }\end{array}$ & $\begin{array}{c}\text { Questionário } \\
\text { com questões } \\
\text { abertas e } \\
\text { fechadas }\end{array}$ & S 1995 \\
\hline $\begin{array}{c}\text { MACHADO, } \\
\text { G. }\end{array}$ & $\begin{array}{c}\text { Um sistema de } \\
\text { acompanhamento } \\
\text { de egressos do } \\
\text { Curso de } \\
\text { Biblioteconomia da } \\
\text { Universidade } \\
\text { Federal do Rio } \\
\text { Grande do Sul }\end{array}$ & $\begin{array}{c}\text { Não } \\
\text { identificada }\end{array}$ & $\begin{array}{c}\text { Não } \\
\text { identificada }\end{array}$ & $\begin{array}{c}\text { Não } \\
\text { identificado }\end{array}$ & 2011 \\
\hline
\end{tabular}




\begin{tabular}{|c|c|c|c|c|c|}
\hline $\begin{array}{l}\text { SANTOS, } \\
\text { Charlene } \\
\text { Maria dos; } \\
\text { PINHO, } \\
\text { Fábio Assis; } \\
\text { AZEVEDO, } \\
\text { Alexander } \\
\text { Wiliam }\end{array}$ & $\begin{array}{l}\text { Perfil dos egressos } \\
\text { do curso de } \\
\text { Biblioteconomia da } \\
\text { Universidade } \\
\text { Federal de } \\
\text { Pernambuco (2005 } \\
\text { a 2010). }\end{array}$ & \begin{tabular}{|} 
Pesquisa \\
exploratória \\
e cujos \\
dados foram \\
analisados \\
de forma \\
quali e \\
quantitativa
\end{tabular} & $\begin{array}{l}\text { Levantamento } \\
\text { bibliográfico }\end{array}$ & $\begin{array}{c}\text { Questionário } \\
\text { com questões } \\
\text { abertas e } \\
\text { fechadas }\end{array}$ & 2013 \\
\hline $\begin{array}{c}\text { FARIA, } \\
\text { Ana Carolina } \\
\text { Cintra; } \\
\text { CASTRO } \\
\text { FILHO, } \\
\text { Cláudio } \\
\text { Marcondes }\end{array}$ & $\begin{array}{l}\text { Profissional da } \\
\text { informação: } \\
\text { estudo dos } \\
\text { egressos no } \\
\text { estado de São } \\
\text { Paulo, mundo do } \\
\text { trabalho, } \\
\text { habilidades e } \\
\text { competências }\end{array}$ & $\begin{array}{c}\text { Não } \\
\text { identificada }\end{array}$ & $\begin{array}{c}\text { Não } \\
\text { identificado }\end{array}$ & $\begin{array}{c}\text { Questionário } \\
\text { com questões } \\
\text { abertas e } \\
\text { fechadas }\end{array}$ & 2014 \\
\hline
\end{tabular}

Fonte: Dados da pesquisa - 2018

Com isso, é possível perceber as diferenças presentes em cada procedimento metodológicos adotado em cada estudo, tendo em vista que em alguns aspectos se diferenciam e se assemelham, com predominância do questionário como o instrumento de coleta de dados mais usado.

\subsection{Produção científica dos trabalhos recuperados a partir da palavra-chave 'mercado de trabalho' que abordam o tema bibliotecário egresso}

A produção científica dos trabalhos cujo tema é mercado de trabalho do bibliotecário egresso, recuperados a partir da palavrachave 'mercado de trabalho', teve claramente um período bastante extenso, a notar pelos anos dessas publicações, que são de 1976 a 2011. Esses trabalhos foram publicados em diferentes periódicos/eventos. Inicialmente, em 1976, pela Revista da Escola de Biblioteconomia da UFMG (atualmente intitulada Perspectivas em Ciência da Informação $^{3}$ ), em seu volume 5 , número 2, da Universidade Federal de Minas Gerais (UFMG). No ano seguinte

\footnotetext{
3 "Foi lançada em 1996, em substituição à Revista da Escola de Biblioteconomia da UFMG" (Portal de periódicos da Escola de Ciência da Informação - UFMG). Portal de Periódicos da Escola de Ciência da Informação - UFMG. Perspectivas em Ciência da Informação. Minas Gerais: UFMG, 2018. Disponível em: <http://portaldeperiodicos.eci.ufmg.br/> Acesso em: 28 maio 2018.
} 
(1977), pela Revista de Biblioteconomia de Brasília (UNB), também no quinto volume, número 2 da Universidade de Brasília.

Oito anos depois, em 1985, na Revista Brasileira de Biblioteconomia e Documentação, no volume 18, número 1/2, da Federação Brasileira de Associações de Bibliotecários, Cientistas da Informação e Instituições (FEBAB). No ano de 1998, a Revista Comunicação \& Informação publicou o primeiro volume, número 1, da Universidade Federal de Goiás (UFG), e em 1999, o Periódico Transinformação, da Pontifícia Universidade Católica de Campinas (PUC-Campinas), publicou seu v. 11, n. 1. Já no ano de 2000, a Revista de Biblioteconomia \& Comunicação (atualmente intitulada Em Questão ${ }^{4}$ ) publicou um artigo. O periódico BIBLOS - Revista do Instituto de Ciências Humanas e da Informação, da Universidade Federal do Rio Grande (FURG), publicou o volume 23, número 2, em 2009. E em 2011, nos anais do XII Encontro Nacional de Pesquisa em Ciência da Informação. Como se vê, os artigos científicos recuperados apresentam diversidade nos canais de divulgação científica.

A maioria dos estudos recuperados foi publicada em periódicos científicos, o que confirma o pensamento de Miranda, Carvalho e Costa $(2018$, p. 2) de que "[...] os periódicos científicos passaram a ser um novo veículo de comunicação da ciência, além de serem mais rápidos do que os livros no que diz respeito à produção e à divulgação".

Quanto aos objetivos das pesquisas, o do primeiro estudo, de autoria de Polke, Araújo e Cesarino (1976, p. 165-166), referente ao projeto de diagnóstico - então desenvolvido pela Escola de Biblioteconomia da Universidade Federal de Minas Gerais, desde agosto de 1974, foi o de "diagnosticar a situação do mercado de trabalho do Bibliotecário e do ensino de Biblioteconomia e verificar o grau de adequação entre ambos".

Ainda sobre esse estudo, teve os objetivos específicos de:

- caracterizar a diversificação do mercado por tipos de instituição;

- caracterizar o tipo de profissional em exercício por idade, sexo, estado civil e status sócio-econômico;

\footnotetext{
4 "Publicada como Revista de Biblioteconomia e Comunicação entre 1986 e 2000 (volumes 1 a 8)" (Em Questão). Em Questão. Revista de Biblioteconomia e Comunicação: v. 1 a 8 (1986 a 2000). Porto Alegre, RS: UFRGS, 2018. Disponível em: <http://seer.ufrs.br/index.php/EmQuestao/issue/view/3439/showToc> Acesso em: 28 maio 2018.
} 
- levantar os motivos que levam à evasão do exercício da profissão;

- determinar as atividades e as dificuldades encontradas no exercício da profissão;

- descrever o grau de satisfação ou insatisfação no desempenho profissional: prestígio, poder, reconhecimento profissional, jornada de trabalho, redistribuição e expectativa salarial. (POLKE; ARAÚJO; CESARINO 1976, p. 167).

O projeto continuou e, no ano seguinte, foram publicados novamente os resultados da pesquisa. O segundo artigo, também de autoria de Polke, Araújo e Cesarino (1977, p. 875), traz os mesmos objetivos da pesquisa anterior.

Já o terceiro estudo teve como objetivo "discutir sobre a situação de mercado de trabalho e salário do profissional bibliotecário". (ALMEIDA JÚNIOR, 1985, p. 62).

O quarto artigo recuperado apresenta um "relato de aprofundada pesquisa sobre a formação profissional e o mercado de trabalho do bibliotecário de Goiânia. A investigação envolveu profissionais recém-formados, além de empresas e instituições que usam (ou não) serviços de informação". (ECHEGARAY et al. 1998, p. 194). procurou,

A pesquisa, segundo Echegaray et al (1998, p. 196-197),

a partir dos depoimentos dos bibliotecários que atuam no mercado de trabalho de Goiânia e das instituições oficiais e/ou empresas, potencialmente empregadoras:

- definir o perfil do profissional bibliotecário;

- verificar as áreas de atuação do bibliotecário;

- identificar possíveis "espaços alternativos" no mercado de trabalho;

- estabelecer uma relação mais dinâmica entre currículo e mercado;

- verificar os aspectos do currículo que inibem ou facilitam a atuação profissional.

O quinto estudo, produzido pelas autoras Beraquet, Ciol, Santos e Stefani (1999, p. 64-65),

[...] teve como objetivo principal identificar as condições de desenvolvimento qualificado do ensino e da pesquisa na Faculdade de Biblioteconomia (FABI) da PUC - Campinas, por meio das seguintes ações:

- Identificar o desempenho do Curso de Graduação em Biblioteconomia face às novas demandas da área; 
- Verificar a congruência entre a formação profissional proporcionada pela FABI PUC-Campinas e a prática profissional de seus egressos;

- Conhecer a avaliação que os docentes do curso fazem de seu próprio trabalho;

- Identificar as principais expectativas das organizações empregadoras quanto ao perfil e à atuação profissional da informação.

O sexto trabalho foi realizado "com os profissionais atuantes em Porto Alegre, egressos do Curso de Biblioteconomia da Universidade Federal do Rio Grande Sul, no período de 1996/2 a 1998/1. Seu objetivo foi o de verificar as condições e as exigências atuais do mercado de trabalho". (KRUEL et al 2000, p. 125).

Quanto ao sétimo estudo, visou "delinear um perfil do egresso do Curso de Biblioteconomia da Universidade Federal do Rio Grande, abrangendo 10 anos (1998-2007)". (SILVEIRA, GONÇALVES, 2009, p. 128).

[...] a pesquisa buscou averiguar, junto aos egressos do Curso de Biblioteconomia da Universidade Federal do Rio Grande, como eles têm avaliado a sua formação acadêmica e técnica e a preparação para o mercado de trabalho, a fim de traçar um perfil dos bibliotecários graduados no período entre 1998 e 2007. (SILVEIRA, GONÇALVES, 2009, p. 127).

Por fim, o oitavo artigo apresentou apenas o resumo, mas, segundo Machado $(2011)^{5}$, seu objetivo foi o de

atribuir um significado à utilização de mecanismos de consulta aos egressos do Curso de Biblioteconomia da Universidade Federal do Rio Grande do Sul - UFRGS, ao avaliar a situação profissional dos egressos do Curso de Biblioteconomia em relação a aspectos de sua trajetória profissional, acadêmica e a expectativas de educação continuada e de participação de atividades na instituição.

Nota-se que os objetivos das produções apresentam como ponto incomum a abordagem do perfil dos egressos de Cursos de Biblioteconomia e os tipos de espaços de sua atuação. Algumas pesquisas apresentam outras vertentes em seus trabalhos, como as que resultaram de um mesmo projeto das autoras Polke, Araújo e Cesarino (1976, 1977), que abordam sobre a evasão profissional, porquanto existem poucos estudos sobre o tema; o estudo

\footnotetext{
${ }^{5}$ Documento não exibido por completo na base de dados, apenas o resumo.
} 
de Echegaray et al (1998), que identifica espaços alternativos de mercado de trabalho e sua relação com o currículo; e a de Beraquet, Ciol, Santos e Stefani (1999), que tratam sobre a avaliação da atuação profissional dos próprios docentes, além das expectativas do mercado em relação à atuação e ao perfil do profissional da informação.

Quanto ao número de palavras-chave, encontraram-se 32, das quais as mais utilizadas pelos autores foram 'mercado de trabalho' com seis ocorrências, 'bibliotecário', com três, e 'Biblioteconomia' com duas. Percebe-se que as palavras-chave que representam as pesquisas são 'mercado de trabalho', 'bibliotecário' e 'Biblioteconomia. É possível que, dentre os estudos expostos na BRAPCl, muitos podem não ter sido resgatados nesta pesquisa, por causa da falta de uso da palavra-chave 'egresso' nas produções. Porém muitas até podem abordar o assunto 'egressos'. Em todos os artigos analisados, em apenas um foi empregada essa palavra-chave.

É importante ressaltar que as palavras-chave são termos centrais do texto que ajudam a recuperar a informação. É um elemento essencial para que os pesquisadores, os estudantes, os professores e a comunidade acadêmica tenham acesso e recuperem os temas de seu interesse.

A esse respeito, Santos (2016, p. 14) diz que são "palavras-chave ou descritores - que exercem a função de pontos de acesso mediante os quais um documento pode ser identificado e recuperado". Quando esses pontos de acesso não estão claros, podem significar barreiras na recuperação da informação.

Um ponto a ser apresentado é em relação às metodologias e aos instrumentos de coleta de dados empregados nessas produções. Para facilitar a exposição, apresenta-se o quadro a seguir.

Quadro 3 - Levantamento dos artigos recuperados pela palavrachave 'mercado de trabalho'

\begin{tabular}{|c|c|c|c|c|c|}
\hline Atores & Título & $\begin{array}{l}\text { Tipo de } \\
\text { pesquisa }\end{array}$ & Método & Instrumento & Ano \\
\hline $\begin{array}{c}\text { POLKE, } \\
\text { A. M. A.; } \\
\text { ARAÚJO, } \\
\text { E. M. B.; } \\
\text { CESARINO, } \\
\text { M. A. N. B. }\end{array}$ & $\begin{array}{c}\text { Análise do } \\
\text { mercado de } \\
\text { trabalho do } \\
\text { bibliotecário em } \\
\text { Belo Horizonte }\end{array}$ & $\begin{array}{c}\text { Levantamento } \\
\text { bibliográfico }\end{array}$ & Levantamento & Questionário & 1976 \\
\hline
\end{tabular}




\begin{tabular}{|c|c|c|c|c|c|}
\hline $\begin{array}{l}\text { POLKE, } \\
\text { A. M. A.; } \\
\text { ARAUUJO, } \\
\text { E. M. B.; } \\
\text { CESARINO, } \\
\text { M. A. N. B. } \\
\end{array}$ & $\begin{array}{c}\text { Análise do } \\
\text { mercado de } \\
\text { trabalho do } \\
\text { bibliotecário em } \\
\text { Belo Horizonte, } \\
\text { Minas Gerais }\end{array}$ & $\begin{array}{c}\text { Levantamento } \\
\text { bibliográfico }\end{array}$ & Levantamento & Questionário & 1977 \\
\hline $\begin{array}{l}\text { ALMEIDA } \\
\text { JÚNIOR, } \\
\text { O. F. }\end{array}$ & $\begin{array}{l}\text { Mercado de } \\
\text { trabalho }\end{array}$ & $\begin{array}{l}\text { Estudo de } \\
\text { caso }\end{array}$ & $\begin{array}{c}\text { Não } \\
\text { identificado }\end{array}$ & $\begin{array}{c}\text { Não } \\
\text { identificado }\end{array}$ & 1985 \\
\hline $\begin{array}{c}\text { ECHEGARAY, } \\
\text { M. A. A; } \\
\text { BARBOSA, } \\
\text { A. M; } \\
\text { GARBELINI, } \\
\text { M. F; } \\
\text { GOUVEIA, } \\
\text { T. G. } \\
\end{array}$ & $\begin{array}{c}\text { Mercado de } \\
\text { trabalho do } \\
\text { profissional } \\
\text { bibliotecário em } \\
\text { Goiânia }\end{array}$ & $\begin{array}{c}\text { Pesquisa de } \\
\text { Campo }\end{array}$ & $\begin{array}{c}\text { Análise } \\
\text { qualitativa } \\
\text { dos dados }\end{array}$ & Questionário & 1998 \\
\hline $\begin{array}{l}\text { BERAQUET, } \\
\text { V.S. M.; } \\
\text { CIOL, R.; } \\
\text { SANTOS, } \\
\text { M. L. K.; } \\
\text { STEFANI, } \\
\text { R. C. }\end{array}$ & $\begin{array}{l}\text { Qualidade de } \\
\text { ensino na FABI- } \\
\text { Campinas face } \\
\text { ao moderno } \\
\text { profissional da } \\
\text { informação }\end{array}$ & $\begin{array}{c}\text { Coleta } \\
\text { qualitativa } \\
\text { (pode-se } \\
\text { entender } \\
\text { como } \\
\text { pesquisa } \\
\text { qualitativa) }\end{array}$ & $\begin{array}{c}\text { Análise } \\
\text { descritiva dos } \\
\text { dados }\end{array}$ & $\begin{array}{l}\text { Questionário; } \\
\text { entrevista; }\end{array}$ & 1999 \\
\hline $\begin{array}{c}\text { KRUEL, } \\
\text { I. R. P.; } \\
\text { FERREIRA, } \\
\text { G. I. S.; } \\
\text { TAZIMA, I. H.; } \\
\text { SCHARNBER } \\
\text { G, J. M. R.; } \\
\text { BONOTTO, } \\
\text { M. E. K. K.; } \\
\text { LAAN, R. H. } \\
\text { V. D. }\end{array}$ & $\begin{array}{c}\text { Mercado de } \\
\text { trabalho do } \\
\text { bibliotecário em } \\
\text { Porto Alegre }\end{array}$ & $\begin{array}{l}\text { Estudo } \\
\text { quantitativo }\end{array}$ & $\begin{array}{c}\text { Não } \\
\text { identificado }\end{array}$ & Questionário & 2000 \\
\hline $\begin{array}{l}\text { SILVEIRA, } \\
\text { J. O. P. B.; } \\
\text { GONÇALVES, } \\
\text { R. B. }\end{array}$ & $\begin{array}{c}\text { Perfil dos } \\
\text { egressos do } \\
\text { Curso de } \\
\text { Biblioteconomia } \\
\text { da Universidade } \\
\text { Federal } \\
\text { do Rio Grande } \\
\text { (1998-2007). }\end{array}$ & $\begin{array}{c}\text { A metodologia } \\
\text { empregada foi } \\
\text { quantitativa }\end{array}$ & $\begin{array}{c}\text { Não } \\
\text { identificado }\end{array}$ & Questionário & 2009 \\
\hline
\end{tabular}




\begin{tabular}{|c|c|c|c|c|c|}
\hline MACHADO, & $\begin{array}{c}\text { Um sistema de } \\
\text { acompanhamento } \\
\text { de egressos do } \\
\text { Gurso de } \\
\text { Giblioteconomia } \\
\text { da Universidade } \\
\text { Federal do Rio } \\
\text { Grande do Sul }\end{array}$ & $\begin{array}{c}\text { Não } \\
\text { identificada }\end{array}$ & $\begin{array}{c}\text { Não } \\
\text { identificada }\end{array}$ & $\begin{array}{c}\text { Não } \\
\text { identificado }\end{array}$ & 2011 \\
\hline
\end{tabular}

Fonte: Dados da pesquisa - 2018

A maioria das metodologias empregadas nas produções para o alcance dos objetivos traçados é do tipo pesquisa quantitativa e de levantamento bibliográfico, seguida pelo estudo de caso e pesquisa qualitativa. Sobre os métodos utilizados nos trabalhos científicos, foram o levantamento bibliográfico, qualitativo e quantitativo. Já o instrumento de coleta de dados mais empregado foi o questionário, seguido pela entrevista.

\subsection{Produção científica dos trabalhos recuperados a partir da palavra-chave 'ex-aluno'}

Quanto ao levantamento bibliográfico realizado na base BRAPCI, a partir do termo de busca 'ex-aluno', só foi recuperado um trabalho. O estudo foi publicado no periódico Perspectivas em Gestão \& Conhecimento em 2016, no volume 6, número 1. De acordo com Queiroz e Paula (2016, p. 6), o objetivo do artigo foi o de

apresentar estratégias orientadas para a conexão entre egressos e suas instituições vislumbrando a construção e o desenvolvimento de vínculos duradouros ainda durante o curso, bem como o acompanhamento pós-formação conduzido por um sólido sistema de informações de ex-alunos, visando por fim, ao aperfeiçoamento das IES.

Assim, depois de expor o objetivo do estudo e fazer a leitura completa do artigo, constatou-se que, apesar de abordar o tema 'ex-aluno', um dos descritores selecionados para esta pesquisa, o trabalho tratou de forma genérica o ex-aluno e não o relacionou com o tema foco desta pesquisa, que é o 'egresso em Biblioteconomia' indexado pela Base de Dados Referenciais de Artigos de Periódicos em Ciência da Informação - BRAPCl. 


\section{CONSIDERAÇÕES FINAIS}

Como já referido, neste relato, foi apresentado um levantamento do tema 'egressos em Biblioteconomia', indexado na Base de Dados BRAPCI. Para recuperar os trabalhos, foram usadas as palavras-chave 'egresso', 'mercado de trabalho' e 'ex-aluno'. Entende-se que o olhar para o profissional que atua no mercado é uma das ações de fortalecimento da área de Biblioteconomia. Por meio do conhecimento do que se produz a respeito, é possível refletir sobre ações possíveis, como, por exemplo, a melhoria da qualidade do ensino nos cursos de formação superior ofertados nas universidades.

$\mathrm{O}$ estudo mostrou a quantidade de pesquisas publicadas a respeito desse tema e seus objetivos e qual o percurso metodológico que se apresenta nos relatos. Assim, constatou-se que existem poucos estudos indexados na base de dados BRAPCI. Depois de feita a busca, a partir da palavra-chave 'egresso', foram recuperados 14 estudos, mas apenas quatro sobre o egresso de Biblioteconomia. Já em relação ao termo 'mercado de trabalho', recuperaram-se 100 artigos. Porém, depois de analisar os resumos e as palavras-chave, o número foi reduzido para oito artigos que abordaram o tema pesquisado. Por fim, a partir da palavra-chave 'ex-aluno', só foi recuperado um estudo.

Esse resultado indica que é preciso dar a devida importância às palavras-chave e atribuir termos representativos e fidedignos ao conteúdo que é abordado no artigo. Isso contribui para que os pesquisadores, os professores, os alunos de graduação e de pós-graduação e quem se interessa por determinado tema temática possam recuperar e acessar mais facilmente a produção científica da área de interesse. Também poderá ajudar os autores a terem o reconhecimento da pesquisa e como um fator de impacto de sua produção acadêmica.

Respondendo a questão-problema, foram levantados e recuperados poucos estudos sobre o tema 'egresso em Biblioteconomia', indexados pela Base de Dados Referenciais de Artigos de Periódicos em Ciência da Informação - BRAPCl, utilizando as palavras-chave. Porém, no geral, só foram recuperados 12 estudos. Isso significa que é preciso direcionar o olhar para esse assunto nas produções científicas na área da Ciência da Informação.

De acordo com os resultados, os objetivos abordados nas pesquisas, de um modo geral, recuperados por meio da palavra-chave 
'egresso', relacionam-se à identificação do perfil dos egressos e sua trajetória profissional; já os recuperados a partir da palavra-chave 'mercado de trabalho' foram: abordagem do perfil dos egressos de Cursos de Biblioteconomia e os tipos de espaços de sua atuação, evasão profissional, espaços alternativos de mercado de trabalho, como também sua relação com o currículo e a avaliação da atuação profissional dos próprios docentes, além das expectativas do mercado em relação à atuação e ao perfil do profissional da informação.

O principal instrumento de coleta de dados empregado nas pesquisas foi o questionário. O estudo mostrou, ainda, que é necessário investigar, pesquisar e produzir mais estudos relacionados ao tema 'egressos em Biblioteconomia', porquanto é relevante para as Instituições de Ensino Superior (IES) acompanharem seus egressos, como forma de ter um feedback, principalmente para melhorar os projetos pedagógicos dos cursos.

\section{REFERÊNCIAS}

ALMEIDA JÚNIOR, O. F. Mercado de trabalho. Revista Brasileira de Biblioteconomia e Documentação, v. 18, n. 1/2, p. 62-77, 1985. Disponível em: <http://www.brapci.inf.br/v/a/10964>. Acesso em: 22 maio 2018.

BERAQUET, V. S. M. O. et al. Qualidade do ensino na Fabi-Campinas face ao moderno profissional da informação. Transinformação, v. 11, n. 1 , p. 63-69, 1999. Disponível em: <http://www.brapci.inf.br/v/a/287>. Acesso em: 18 maio 2018.

BERNARDINO, Maria Cleide Rodrigues; ALENTEJO, Eduardo da Silva. Ranking da produção científica dos Programas de Pós-graduação em Ciência da Informação no Brasil. Brazilian Journal of Information Science: Research Trends, v. 8, n. 1/2, 2014. Disponível em: <http://www2.marilia.unesp.br/ revistas/index.php/bjis/article/view/4255/3094>. Acesso em: 16 out. 2017.

BRAPCI - Base de Dados em Ciência da Informação. Acervo de Publicações Brasileiras em Ciência da Informação. Universidade Federal do Paraná. Disponível em: < http://www.brapci.ufpr.br/brapci/>. Acesso em: 12 set. 2017.

BRASIL. Lei № 4.084, de 30 de junho de 1962. Dispõe sobre a profissão de bibliotecário e regula seu exercício. Disponível em: <http://www.planalto. gov.br/ccivil_03/LEIS/1950-1969/L4084.htm> Acesso em: 06. jan. 2020.

BRASIL. Parecer CNE/CES n 492/2001, aprovado em 3 de abril de 2001. Aprova as Diretrizes Curriculares Nacionais dos Cursos de Arquivologia, Biblioteconomia, Ciências Sociais, Antropologia, Ciência Política, Sociologia, Comunicação Social, Filosofia, Geografia, História, Letras, Museologia e Serviço Social. Disponível em: <http://portal.mec.gov.br/ cne/arquivos/pdf/CES0492.pdf> Acesso em: 06. jan. 2020. 
BUFREM, Leilah Santiago. Relações construídas no campo de conhecimento da Ciência da Informação no Brasil: a literatura periódica científica em foco. Informação \& Informação, Londrina, v. 18, n. 3, p. 68-97, set./dez. 2013. Disponível em: <http://www.uel.br/revistas/uel/index.php/informacao/ article/view/16705>. Acesso em: 10 jun. 2018.

CARIBÉ, Rita de Cássia do Vale. Comunicação científica: reflexões sobre o conceito. Inf. \& Soc.: Est., João Pessoa, v. 25, n. 3, p. 89-104, set./dez., 2015. Disponível em: http://www.periodicos.ufpb.br/ojs/index.php/ies/ article/view/23109/14530 Acesso em: 09 mar. 2019.

CARVALHO, Luciana Moreira; BARBOSA NETO, Pedro Alves. Análise do mercado de trabalho como estratégia para a mediação da formação do bibliotecário: o caso dos egressos do Curso de Graduação em Biblioteconomia da Universidade Federal do Rio Grande do Norte. In: ENCONTRO NACIONAL DE PESQUISA EM CIÊNCIA DA INFORMAÇÃO, 17, 2016, Salvador. Anais... Salvador: UFBA, 2016. Disponível em:<http://repositorios.questoesemrede.uff. br/repositorios/bitstream/handle/123456789/3450/2016_GT6-

CO_15.pdf?sequence=1> Acesso em: 09 out. 2017.

COELHO, Maria do Socorro da Costa. Nas águas o diploma: o olhar dos egressos sobre a política de interiorização da UFPA em Cametá-Pa. 2008. 330 f. Tese (Doutorado em Educação) - Pontifícia Universidade Católica de São Paulo, São Paulo, 2008. Disponível em: <https://tede2.pucsp.br/ handle/handle/10046> Acesso em: 09 mar. 2019.

ECHEGARAY, M. A. A. et al. Mercado de trabalho do profissional bibliotecário em Goiânia. Comunicação \& Informação, v. I, n. 1, p. 194-211. jan./jun. 1998. Disponível em: <http://www.brapci.inf.br/v/a/22345>. Acesso em: 18 maio 2018.

FARIA, A. C. C.; CASTRO FILHO, C. M. Profissional da informação: estudo dos egressos no estado de São Paulo, mundo do trabalho, habilidades e competências. Ponto de Acesso, v. 8, n. 3, 2014. Disponível em: <http://www.brapci.ufpr.br/brapci/v/a/21545>. Acesso em: 12 set. 2017. GABRIEL JUNIOR, Rene Faustino. Geração de indicadores de produção e citação científica em revistas de Ciência da Informação: estudo aplicado à base de dados BRAPCI. 2014. 140 f. Dissertação (Mestrado) Universidade Estadual Paulista Júlio de Mesquita Filho, Faculdade de Filosofia e Ciências, 2014. Disponível em: <http://hdl.handle.net/ 11449/123338>. Acesso em: 10 jun. 2018.

KRUEL, I. S. R. P. et al. Mercado de trabalho do bibliotecário em Porto Alegre. Revista de Biblioteconomia \& Comunicação, v. 8, n. 1, p. 125-134, 2000.

Disponível em: <http://www.brapci.inf.br/v/a/4624>. Acesso em: 18 maio 2018. MACHADO, G. Um sistema de acompanhamento de egressos do Curso de Biblioteconomia da Universidade Federal do Rio Grande do Sul. In: ENCONTRO NACIONAL DE PESQUISA EM CIÊNCIA DA INFORMAÇÃO, 12., 2011. Brasília. Anais... Brasília: Faculdade de Ciência da Informação da UNB, 2011. Disponível em: <http://www.brapci.inf.br/ 
index.php/article/view/0000011197/a602e53de0e43d9f0f9766cc82e27034>. Acesso em: 18 maio 2018.

MARCELO, Júlia Fernandes; HAYASHI, Maria Cristina Piumbato Innocentini. Estudo bibliométrico sobre a produção científica da área da Sociologia da Ciência. Informação \& Informação, [S.I.], v. 18, n. 3, p. 138-153, set. 2013. Disponível em: <http://www.uel.br/revistas/uel/index.php/informacao/ article/view/8413>. Acesso em: 27 out. 2017.

MEDEIROS, José Mauro Gouveia de; VILAN FILHO, Jayme Leiro. Análise da produção científica da Arquivologia no Brasil: uma revisão de literatura. Informação \& Informação, [S.I.], v. 21, n. 3, p. 34-62, set./dez., 2016. Disponível em: <http://www.uel.br/revistas/uel/index.php/informacao/article/ view/26125/20727>. Acesso em: 24 out. 2017.

MIGUÉIS, Ana et al. A importância das palavras-chave dos artigos científicos da área das Ciências Farmacêuticas, depositados no Estudo Geral: estudo comparativo com os termos atribuídos na MEDLINE. InCID: Revista de Ciência da Informação e Documentação, Ribeirão Preto, v. 4, n. 2, p. 112-125, dec. 2013. Disponível em: <http://www.revistas.usp.br/incid/article/view/ 69284/71742>. Acesso em: 25 out. 2017.

MIRANDA, A. C. C.; CARVALHO, E. M. R.; COSTA, M. I. O impacto dos periódicos na comunicação científica. BIBLOS - Revista do Instituto de Ciências Humanas e da Informação, v. 32, n. 1, p. 1-22, 2018. Disponível em: <https://periodicos.furg.br/biblos/article/view/7177>. Acesso em: 09 mar. 2019.

MOREIRA, Luciana de Albuquerque. As bibliotecas universitárias de Portugal e do nordeste do Brasil: estudo sobre o impacto e mediação das tecnologias. Natal: EDUFRN, 2018. Disponível em: <https://repositorio.ufrn. br/jspui/handle/123456789/25585> Acesso em: 20 jul.2018.

MÜLLER, M. S.; FERNANDES, R. R. P. M. E.; SANCHES, M. S. Com a palavra os egressos...: avaliação do Curso de Biblioteconomia da UEL. Informação \& Informação, v. 3, n. 2, p. 43-64, 1998. Disponível em: <http://www.brapci.ufpr.br/brapci/v/a/6093>. Acesso em: 12 set. 2017. OLIVEIRA, E. F. T.; GRÁCIO, M. C. C. A produção científica em organização e representação do conhecimento no Brasil: uma análise bibliométrica do GT-2 da Ancib. In: ENCONTRO NACIONAL DE PESQUISA DA ANCIB - ENANCIB, 10., 2009 João Pessoa. Anais... João Pessoa: ANCIB, 2009. Disponível em: <http://enancib.ibict.br/index.php/enancib/ xenancib/paper/view/3292/2418> Acesso em: 26 abr.2018.

PALETTA, Francisco Carlos; SILVA, Armando Melheiro da. Atuação do profissional da informação na organização do conhecimento na web de dados. In: SIMÕES, Maria das Graças; BORGES, Maria Manoel (Coord.). Tendências atuais e perspectivas futuras em organização do conhecimento: atas do III Congresso ISKO Espanha e Portugal - XIII ISKO Espanha. p. 167-176

POLKE, A. M. A.; ARAÚJO, E. M. B.; CESARINO, M. A. N. B. Análise do mercado de trabalho do bibliotecário em Belo Horizonte. Revista da Escola 
de Biblioteconomia da UFMG, v. 5, n. 2, p. 165-177, 1976. Disponível em: <http://www.brapci.inf.br/v/a/10065>. Acesso em: 22 maio 2018.

POLKE, A. M. A.; ARAÚJO, E. M. B.; CESARINO, M. A. N. B. Análise do mercado de trabalho do bibliotecário em Belo Horizonte, Minas Gerais. Revista de Biblioteconomia de Brasília, v. 5, n. 2, p. 875-910, 1977. Disponível em: <http://www.brapci.inf.br/v/a/8684>. Acesso em: 22 maio 2018.

PROJETO Pedagógico do Curso de Graduação em Biblioteconomia da Universidade Federal do Rio Grande do Norte. Nata, 2017. 289p.

QUEIROZ, T. P.; PAULA, C. U. P. O. A. C. O relacionamento com egressos como estratégia organizacional para o desenvolvimento das instituições de educação superior. Perspectivas em Gestão \& Conhecimento, v. 6, n. 1, 2016. Disponível em: <http://www.brapci.inf.br/v/a/20343>. Acesso em: 23 maio 2018.

SANTOS, C. M.; PINHO, F. B. A.; AZEVEDO, A. W. Perfil dos egressos do Curso de Biblioteconomia da Universidade Federal de Pernambuco (2005 a 2010). Revista Digital de Biblioteconomia \& Ciência da Informação, v. 11, n. 2, 2013. Disponível em: <http://www.brapci.ufpr.br/brapci/v/a/13368>. Acesso em: 12 set. 2017.

SANTOS, Raimunda Fernanda dos. Modelos colaborativos de indexação social e sua aplicabilidade na Base de Dados Referencial de Artigos de Periódicos em Ciência da Informação (BRAPCI). 184f. Dissertação (Mestrado em Ciência da Informação) - Universidade Federal de Pernambuco, Recife, 2016. Disponível em: <https://repositorio.ufpe.br/ handle/123456789/17218> Acesso em: 09 mar. 2019.

SILVEIRA, J. O. P. B.; GONÇALVES, R. B. Perfil dos egressos do Curso de Biblioteconomia da Universidade Federal do Rio Grande (1998-2007).

BIBLOS - Revista do Instituto de Ciências Humanas e da Informação, v. 23, n. 2, p. 127-135, 2009. Disponível em: <http://www.brapci.inf.br/v/a/8439>. Acesso em: 11 maio 2018.

TARGINO, Maria das Graças; TORRES, Názia Holanda. Comunicação científica além da Ciência. Ação Midiática - Estudos em Comunicação, Sociedade e Cultura. [S.I.], jul. 2014. Disponível em: <https://revistas.ufpr. br/acaomidiatica/article/view/36899/22924>. Acesso em: 26 abr. 2018.

VALENTIM, M. L. P. (Org.). O profissional da informação: formação, perfil e atuação profissional. São Paulo: Polis, 2000.

VALENTIM, Marta Lígia Pomim. Formação: competências e habilidades do profissional da informação. In: VALENTIM, Marta Lígia Pomim (Org.).

Formação do profissional da informação. São Paulo: Polis, 2002. p. 117-132.

Recebido em: 09/04/2019

Aceito em: 20/11/2019 